DOI: 10.21892/978-958-5547-64-3.9

\title{
9. La vivienda de interés social en Cartagena: un análisis crítico en torno de la satisfacción del derecho a la vivienda digna ${ }^{1}$
}

Rafaela Sayas Contreras ${ }^{2}$ Oswaldo Mercado Pedraza ${ }^{3}$

\section{Introducción}

La necesidad de vivienda digna en Colombia es una situación apremiante que se hace extensiva a la ciudad de Cartagena de Indias, aspecto negativo que contrasta con el creciente número de construcciones, más los múltiples proyectos de inversión públicos y privados en desarrollo. De hecho, según datos del Departamento Administrativo Nacional de Estadística (DANE, 2016), el déficit de vivienda en Cartagena es de 78 mil casas, con un indicador del 37,2 \%. Así las cosas, la ciudad ocupa el segundo lugar en el país con el mayor déficit habitacional, y con viviendas que no solo carecen o tienen problemas de servicios públicos, sino de las normas mínimas de seguridad y salubridad.

Uno de los deseos del ser humano es tener un techo donde poder vivir, más aún si tiene familia. De tal manera que el hecho de obtener una vivienda se ha convertido en un derecho reconocido en el marco de los derechos sociales. Por su misma naturaleza, constituye un reto de gran

1 Informe de avance del proyecto: "Observatorio de territorio urbano y patrimonio histórico", que viene ejecutando el grupo de investigación "Conflicto y Sociedad" de la Universidad de Cartagena.

2 Abogada de la Universidad de Cartagena, docente de la misma universidad en grado y posgrado, lider del grupo de investigación conflicto y sociedad de la Universidad de Cartagena. Especialista en Conciliación y resolución de conflictos de la Universidad de Cartagena. Especialista en Derecho Financiero de la Universidad del Rosario. Magíster en Derecho de la Universidad Nacional de Colombia. Doctora en Sociología de la Universidad de Belgrano, Argentina.

3 Abogado de la Universidad de Cartagena, semillerista del grupo de investigación Conflicto y Sociedad de la Universidad de Cartagena. 
magnitud para los Estados nacionales y para los ciudadanos de escasos recursos económicos.

Es imperiosa la necesidad de las personas más pobres de tener una vivienda denominada de interés social. Por ello, este trabajo de investigación dará cuenta de la brecha entre aspectos normativos y sociales relacionados con la vivienda digna, y la adjudicación de este tipo de viviendas en la ciudad de Cartagena. Se efectuará un abordaje cualitativo, jurídico dogmático, con fundamento en información secundaria, análisis que girará en torno de la siguiente pregunta problematizadora:

¿Satisfacen las viviendas de interés social- VIS el derecho de los usuarios a poseer la vivienda digna de conformidad con los postulados del estado social de derecho? ¿Qué tipo de entes de control y acciones judiciales amparan a los adjudicatarios de VIS en caso de vulneración de sus derechos?

El trabajo se ceñirá al siguiente orden: en primer lugar se determinará el alcance del derecho a la vivienda y el sitial que ocupa dentro de los derechos sociales. Luego se efectuará un recuento de la evolución de la VIS en Cartagena, y el respectivo análisis sobre los beneficiarios de la construcción de VIS. Por último, se estudia el tipo de acciones judiciales que amparan la protección de este derecho conforme a las normas vigentes. La escala temporal del análisis está macada por la finalización de la década de los años noventa, con algunas de las consecuencias que se han venido generando en los años posteriores. Los fundamentos legales de nuestro enfoque teórico son los que están en la normativa de la Constitución Política de Colombia, como la Ley 9 de 1.989, Ley 388 de 1.997, normas internacionales en la materia, sentencias judiciales e información periodística relevante sobre esta temática de las viviendas, para posteriormente plantear las conclusiones respectivas.

\section{La vivienda digna}

El Diccionario de la Real Academia de la Lengua (DRAE) define la vivienda como un lugar cerrado y cubierto construido para ser habitado por personas. En Colombia, cuando se trata el tema de vivienda, no se habla de una vivienda cualquiera, esta debe ser digna, derecho que ha 
sido elevado a rango constitucional, en el artículo 51, relacionado con los derechos sociales, económicos y culturales:

Todos los colombianos tienen derecho a vivienda digna. El Estado fijará las condiciones necesarias para hacer efectivo este derecho y promoverá planes de vivienda de interés social, sistemas adecuados de financiación a largo plazo y formas asociativas de ejecución de estos programas de vivienda. (Art. 51)

La vivienda y el hábitat han sido reconocidos y consagrados en los instrumentos más relevantes del derecho internacional de los Derechos Humanos con una categorización propia, integrándose en el derecho humano a la vivienda adecuada. Este derecho humano se encuentra contemplado expresamente en los máximos instrumentos jurídicos de carácter universal como la Declaración Universal de Derechos Humanos, del 10 de diciembre de 1948, que en su artículo 25, numeral 1, reza:

\section{Artículo 25:}

1. Toda persona tiene derecho a un nivel de vida adecuado que le asegure, así como a su familia, la salud y el bienestar, y en especial la alimentación, el vestido, la vivienda, la asistencia médica y los servicios sociales necesarios; tiene asimismo derecho a los seguros en caso de desempleo, enfermedad, invalidez, viudez, vejez y otros casos de pérdida de sus medios de subsistencia por circunstancias independientes de su voluntad.

Por otro lado, el Pacto Internacional de Derechos Económicos Sociales y Culturales, del 16 de diciembre de 1966, artículo 11, numeral 1, plantea:

\section{Artículo 11:}

1. Los Estados Partes en el presente Pacto reconocen el derecho de toda persona a un nivel de vida adecuado para sí y su familia, incluso alimentación, vestido y vivienda adecuados, y a una mejora continua de las condiciones de existencia. Los Estados Partes tomarán medidas apropiadas para asegurar la efectividad de este derecho, reconociendo a este efecto la 
importancia esencial de la cooperación internacional fundada en el libre consentimiento.

Investigando más en el fondo del asunto, encontramos que en el derecho interno, existen leyes relacionadas con el derecho urbano que aluden a la materia, como la Ley 9 de 1.989, la Ley 388 de 1.997, la Ley 400 de 1.997. Además de diferentes actualizaciones consignadas en las leyes 810 de 2.003, 902 de 2.004 y 1.537 de 2.012, las cuales han intentado dotar herramientas jurídicas a la sociedad en general, para el manejo de la vivienda de interés social. También el decreto No. 0977 del 20 de noviembre de 2.001, ayuda a nutrir esta área del derecho, por medio del cual se adoptó el Plan de Ordenamiento Territorial del Distrito Turístico y Cultural de Cartagena de Indias. Tampoco la construcción de viviendas está exenta del cumplimiento de las normativas de derecho administrativo y urbano.

A continuación tomaremos como referente los parámetros establecidos por la Defensoría del Pueblo, relacionados con las condiciones mínimas que debe tener una vivienda, de acuerdo a los requerimientos legales para la satisfacción de este derecho:

Una vivienda digna debe ofrecer seguridad y condiciones mínimas que la hagan habitable. Una vivienda adecuada debe ser habitable, en el sentido de tener espacio suficiente según el número de habitantes, contar con los servicios públicos domiciliarios, además de calidad de estructura, entradas naturales de luz, corrientes de aire y espacios para la recreación y el esparcimiento.

El Estado es el encargado de autorizar los usos que puede tener el suelo, bien sea para vivienda, comercio e industria, entre otros. La vivienda debe estar ubicada en una zona autorizada. No debe aceptarse por ningún motivo que la residencia se encuentre en una zona de riesgo.

Los constructores de vivienda deben sujetarse a las normas de construcción estipuladas por la ley y asegurarse de que estas cumplan parámetros de seguridad y calidad. Las autoridades no solo deben expedir estas normas, sino vigilar su cumplimiento e imponer sanciones, si es del caso. 
Directrices que servirán como referente en el desarrollo del trabajo que se presenta, puesto que no se trata de cualquier vivienda, ya que la misma debe tener la característica de ser "digna". Con lo cual encontramos conceptualmente la dualidad de vivienda digna/indigna, circunstancia que no es menor si se trata de un derecho reconocido por la legislación internacional.

\section{Evolución histórica de las viviendas de interés social en}

\section{Cartagena}

La reorganización del Ministerio de Vivienda, ciudad y territorio es reciente, puesto que la entidad encargada de regular nacionalmente lo concerniente a la construcción de viviendas sociales era el Instituto de Crédito Territorial (en adelante ICT). Ente que se encargaba de coordinar la financiación de proyectos de construcción de vivienda para las personas de más escasos recursos. Las construcciones que se hicieron en Cartagena a partir de los años setenta, fueron bastante aceptables desde el punto de vista del área de construcción. Proyectos de vivienda tales como Los Caracoles, Los Cerros, El Socorro, Blas de Lezo, Las Gaviotas, San Pedro, Nuevo Bosque, Almirante Colón, Chiquinquirá, Los Calamares, Villa Rosita, Chapacuá, Las Palmeras, eran un claro ejemplo de que las cosas, aparentemente, iban a mejorar en cuanto a las viviendas para las personas de menores recursos, aunque no podemos desconocer que también se dieron algunos inconvenientes dentro la construcción de estos proyectos de vivienda.

A la par de los proyectos financiados por el ICT, también hubo proyectos financiados por la banca privada, bajo el sistema de financiamiento UPAC (Unidad de poder adquisitivo constante), cuyo estruendoso fracaso llevó a los usuarios del sistema y dueños de las viviendas a un endeudamiento irracional e injusto. Este sistema fue declarado inexequible por la Corte Constitucional Colombiana. En septiembre de 1.999 la Corte Constitucional prohibió el pago de intereses sobre intereses en las obligaciones de vivienda (anatocismo). El magistrado ponente de dicha decisión fue José Gregorio Hernández, quien dejó sin piso jurídico varias normas del Estatuto Financiero. Al entender que la deuda hipotecaria para adquisición de vivienda se hacía impagable por parte de los deudores hipotecarios, cuando los bancos hacían la proyección financiera calculando interés sobre el capital, y una vez liquidados los intereses, generaban 
nuevamente intereses, lo que ocasionaba que la deuda no decrecía, sino que aumentaba, quedando la obligación hipotecaria con el banco superior al costo de mercado del inmueble, sobre el cual recaía la obligación hipotecaria.

Quiere decir ello que si una persona accedía a un crédito de vivienda con la banca privada, la obligación se hacía impagable para el deudor, reportando una pérdida para el propietario de la vivienda, quien padecía el remate judicial de su vivienda, pero con una ganancia siempre para el sector bancario. En ese orden de ideas, el sistema de endeudamiento en UPAC cayó, estableciéndose nuevos parámetros de financiación de vivienda con la banca privada.

Por otra parte es necesario señalar que los terrenos de expansión de la vivienda social con financiación pública, se extendió hacia terrenos de la periferia. Circunstancia que hoy se mantiene todavía, y que denotan la tensión de las viviendas y la problematización de la proyección hacia la periferia. De hecho, la organización de la ciudad y el urbanismo son temas de interés internacional. De acuerdo con la Carta Mundial del Derecho a la Ciudad realizado en el año 2.004, las ciudades están lejos de ofrecer condiciones y oportunidades equitativas a sus habitantes. La población urbana, en su mayoría, está privada o limitada -en virtud de sus características económicas, sociales, culturales, étnicas, de género y edadpara satisfacer sus más elementales necesidades. Este contexto favorece el surgimiento de luchas urbanas como formas sociales de resistencia contra la globalización y la lucha por los derechos ciudadanos.

Frente a esta realidad la sociedad civil reunida en el marco del Primer Foro Social Mundial 2.001, discutieron y asumieron el desafío de construir un modelo sustentable de sociedad y vida urbana, basado en los principios de solidaridad, libertad, equidad, dignidad y justicia social. Uno de sus fundamentos radica en el respeto por las diferentes culturas urbanas, y el equilibrio entre lo urbano y lo rural. Desde el I Foro Social Mundial en la ciudad de Porto Alegre, un conjunto de movimientos populares, organizaciones no gubernamentales, asociaciones profesionales, foros y redes nacionales e internacionales de la sociedad civil comprometidas con las luchas sociales por ciudades justas, democráticas, humanas e sustentables, vienen construyendo una carta mundial del derecho a la ciudad que traduzca los compromisos y medidas que deben ser asumidos por la 
sociedad civil, gobiernos locales y nacionales, y organismos internacionales para que todas las personas vivan con dignidad en nuestras ciudades.( Carta Mundial por el Derecho a la Ciudad, 2.005: 184)

Así las cosas, se debe decir que las viviendas sociales en Cartagena, no se encuentran en el núcleo de la ciudad. Veamos la ubicación de las VIS en el territorio:

\section{Mapa 1}

Ubicación geográfica VIS en Cartagena

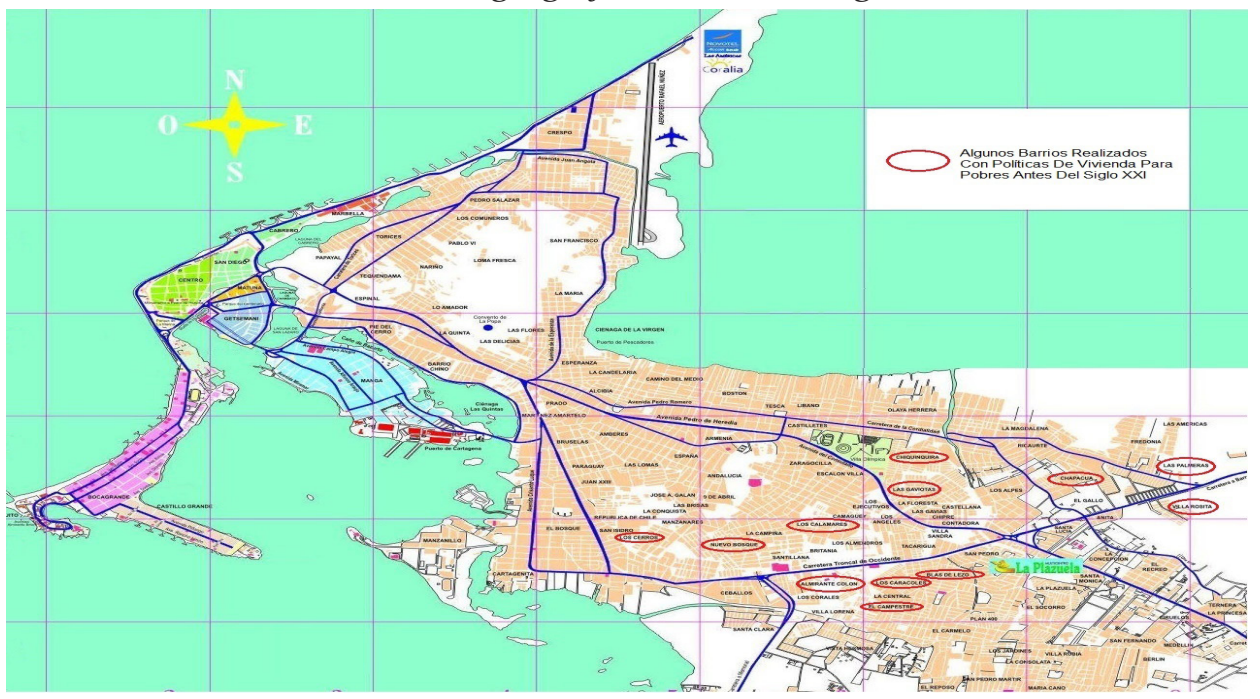

Fuente: http://www.quetiempo.es/fotos/mapa-de-cartagena (archivo editado)

Del plano se puede apreciar que los emprendimientos en VIS no son hacia el centro del Distrito sino hacia la periferia, aspecto que revela un lado vulnerable en el tipo de terrenos y acceso a bienes y servicios por parte de los ocupantes de VIS. Dicho en perspectiva crítica se aprecia cómo los pobres no tienen derecho de vivienda en la ciudad sino en la periferia.

\section{VIS: vivienda para pobres o para el mercado}

Las políticas de vivienda comienzan bien, pero se transforman cuando entran en este sector los gremios privados con proyectos urbanísticos que están apoyados financieramente por la banca comercial. En el pasado ya se hablaba de UVR, (Unidad de Valor Real constante) que fue creada por 
el Congreso de la Republica, mediante la Ley 546 de 1.999 (en reemplazo de UPAC), vigente desde el primero de enero del año 2.000. La incursión de dineros de la banca privada, configura un redimensionamiento en la vivienda social, aunada a los procesos licitatorios que tienen ocurrencia en el contexto local.

Este nuevo tipo de Viviendas de Interés Social ya no son tan dignas como se pregona o pretende. A causa de diversas razones, entre las cuales resalta que estas viviendas son de inferior calidad en comparación con las construidas directamente por el gobierno nacional, a través del Instituto de Crédito Territorial (ICT). Tomando en cuenta aspectos o factores como la calidad de la estructura, la dimensión de la superficie y la excelencia de los materiales. Algunos de estos proyectos diseñados especialmente por la empresa privada durante la década de los 90 del siglo XX, han resultado proyectos problemáticos para los ciudadanos que accedieron a ellos, como en los casos, entre otras, de Villa Liliana, Mirador de Zaragocilla, Nueva Granada, Ciudadela India Catalina, El Rodeo (este pertenecía al distrito de Cartagena, y hoy forma parte de Turbaco).

Entre los proyectos de vivienda más graves se encuentran, inclusive, algunos con acciones populares falladas, como es el caso de la Ciudadela India Catalina, por la violación de las normas urbanísticas. Tales como licencia ambiental, licencia de construcción y licencia urbanística. También violación del Acuerdo 23 Bis De 1.996, denominado Manual De Ordenamiento Administrativo del Espacio Urbano del Distrito de Cartagena. Específicamente en la Loma del Marion (Periódico el Universal, 2.011) donde estaba ubicada la tercera etapa de la Urbanización Nueva Granada. Además, cabe resaltar el escaso control por parte de las autoridades correspondientes que generaron construcciones ilegales (Periódico El Universal, 2.012), sin el seguimiento real que se debía hacer a los llamados subsidios para dichas viviendas, así como la construcción en terrenos no aptos para tal fin, y la violación de los derechos del consumidor. Estas construcciones anotadas quedaron sin concluir, en el marco de lo que inicialmente había sido planeado, es decir, vulnerando, por supuesto, la información dada a estos compradores.

La anterior situación ha traído como consecuencia negativa que compradores de vivienda de interés social les tengan desconfianza a los constructores privados, que son las entidades que regulan y controlan 
este tipo de proyectos. Esto a su vez genera conflictos en la sociedad y, por supuesto, hace nugatorios derechos constitucionalmente reconocidos, que suponen más empobrecimiento para los compradores de este tipo de viviendas.

\section{Consecuencias generadas por los proyectos VIS en Cartagena y las acciones judiciales}

Los diversos problemas que han presentado los proyectos de construcción de VIS, han ocurrido en Cartagena a finales del siglo XX, desencadenando algunas consecuencias negativas tanto a las personas como al Distrito de Cartagena como tal. Sobre el particular, se han interpuesto diferentes acciones judiciales, como las acciones constitucionales de tutela populares y de grupo, esto por parte de las comunidades para poder defender el derecho a la vivienda digna consagrado en el artículo 51 de la Constitución Nacional. Asuntos sociales ante el cual el derecho debe ofrecer respuestas concretas frente a las diferentes vulneraciones sufridas por los ciudadanos.

En la actualidad hay algunas sentencias proferidas como consecuencia de Acciones judiciales instauradas, como por ejemplo: radicado 13-001-3331-004-2008-00092-00 del Juzgado Cuarto Administrativo del Circuito Judicial de Cartagena, y, la 13-001-23-33-000-2012-00034-00 del Tribunal Administrativo de Bolívar, Sala de Decisión de Oralidad No. 2 que han sido falladas en favor de las comunidades que las han interpuesto (Ciudadela India Catalina). También de acción popular como la de radicado 0041999-0002-00 (Nueva Granada) del Tribunal Administrativo de Bolívar, confirmado en segunda instancia, según el radicado AP-118 del Consejo de Estado, que falló en pro de los demandantes. Esta circunstancia afecta de manera negativa al Estado, porque conlleva al detrimento del patrimonio económico público, ya que es al Distrito de Cartagena al que le corresponde pagar los daños materiales causados.

Cabe anotar que en todas estas decisiones de los juzgados y tribunales, se ha imputado responsabilidad tanto de los

constructores como del Distrito de Cartagena. Sin embargo, en cuanto a la responsabilidad de las constructoras, se aprecia 
un comportamiento particular, que indica una evasión de responsabilidad jurídica, por los efectos de la declaración de algunas de ellas en "quiebra" o liquidación obligatoria, mediante estrategias jurídicas, cobijándose bajo la extinta Ley 550 de reestructuración empresarial. O también en la posterior Ley 1116 de 2.006, referida a la insolvencia empresarial, evitando así tener que pagar por los daños que hayan causado. En cuanto a esto último, el artículo 125 de la Ley 388 del 18 julio de 1.997, que modifica la Ley $9^{a}$ de 1989, y la Ley $3^{a}$ de 1.991, nos dice:

Artículo 125. Las personas naturales o jurídicas que se dediquen a la construcción y enajenación de inmuebles destinados a vivienda y que se encuentren en las situaciones previstas en los numerales 1 y 6 del artículo 12 de la Ley 66 de 1.968, podrán acceder al trámite de un concordato o de una liquidación obligatoria, en los términos previstos en la Ley 222 de 1.995 o en las normas que la complementen o modifiquen, siempre y cuando estén desarrollando la actividad urbanística con sujeción a las disposiciones legales del orden nacional, departamental, municipal o distrital.

Lo cual quiere decir que ninguna empresa constructora de viviendas de interés social debe ser enviada a liquidación obligatoria por parte de la superintendencia de sociedades, si no está cumpliendo la legalidad exigida por la normatividad colombiana. Como, por ejemplo, tener en regla todas las licencias, como la ambiental y la de construcción o urbanística.

En cuanto a los fallos anotados arriba, podemos agregar que declararon responsables a la Alcaldía de Cartagena D.T. y C y a la Constructora Gabón, de la vulneración de los derechos e intereses colectivos al goce de un ambiente sano, seguridad y salubridad pública en la realización de construcciones, edificaciones y desarrollos urbanos. Así como a las gestiones administrativas, técnicas, financieras, presupuestales y contractuales para la consecución de los recursos para la realización de estudios técnicos y viabilidad de construir un canal para el manejo del drenaje de las aguas pluviales. La declaración de vulneración de los derecho de los consumidores y usuarios al goce del espacio público, y la realización de las construcciones, edificaciones y desarrollo urbano respetando las disposiciones jurídicas, y 
dando preeminencia a la calidad de vida de los habitantes. Además, en el caso de la tercera etapa de construcción de Nueva Granada, se ordenó el estudio técnico a la Alcaldía y la Constructora el Cerro para la reubicación de los habitantes

Estas consecuencias negativas también han desmejorado a la población, tanto en lo económico como en lo moral. Son muchas las personas que han perdido su dinero en este tipo de proyectos, que nunca fueron realizados o han quedado esclavizados a la banca privada pagando cuotas muy onerosas, que no se corresponde con lo construido. Esto claramente va en contravía de la responsabilidad social que tiene este sector respecto a sus stakeholders (Vargas-Chaves \& Marrugo-Salas. 2015).

\section{Acerca del control de entidades sobre las VIS}

El control y la vigilancia del buen desarrollo de viviendas de interés social, por parte de las entidades estatales, recae directamente sobre las alcaldías, a través de su oficina de control urbano. En el caso específico de Cartagena de Indias, lo hacen también las alcaldías locales, las cuales deben estar atentas y supervisando para que el desarrollo de estos proyectos urbanísticos lleguen a feliz término.

Así mismo, la Superintendencia de Sociedades ejerce control sobre estas empresas constructoras, aunque no lo haga desde el punto de vista de la construcción como tal, sí le corresponde supervisar el manejo administrativo correcto que deben tener estas empresas. También las curadurías urbanas hacen un control inicial, ya que son ellas las que expiden las licencias de construcción y urbanismo. En cuanto a la licencia ambiental, en el caso específico de Cartagena, lo hace la Entidad Público Ambiental - EPA. Frente a la vulneración de derechos en la construcción de VIS, la ley tiene que ofrecer respuestas concretas. De hecho, para proteger a los compradores, tal como ya fue anunciado, en Colombia existen acciones constitucionales tales como la acción de tutela, acción popular y acción de grupo. Estas se pueden impetrar para defender los intereses de la población afectada por la compra de viviendas de interés social, y que hayan sido aprovechados en su necesidad de adquisición de viviendas. Así las cosas, 
podemos señalar las siguientes herramientas en defensa de los intereses y derechos vulnerados:

i. Acción popular: Las acciones populares son el mecanismo de protección de los derechos e intereses colectivos y difusos (los relacionados con ambiente sano, moralidad administrativa, espacio público, patrimonio cultural, seguridad y salubridad pública, servicios públicos, consumidores y usuarios, libre competencia económica, etc.). La misma está prevista en el primer inciso del artículo 88 de la Constitución Política de 1.991, que reza:

"La ley regulará las acciones populares para la protección de los derechos e intereses colectivos, relacionados con el patrimonio, el espacio, la seguridad y la salubridad públicos, la moral administrativa, el ambiente, la libre competencia económica y otros de similar naturaleza que se definen en ella.

"Así mismo, definirá los casos de responsabilidad civil objetiva por el daño inferido a los derechos e intereses colectivos".

ii. Acción de grupo: La segunda parte del artículo 88 de la Constitución Política se refiere a un mecanismo cercano a las acciones populares, pero diferenciable porque se trata de las llamadas acciones de grupo o de clase. Fueron consagradas en el inciso segundo del artículo 88 de la Carta Política, enseguida de las acciones populares, dice que la ley: "También regulará las acciones originadas en los daños ocasionados a un número plural de personas, sin perjuicio de las correspondientes acciones particulares".

La Ley 472 de 1.998 desarrolló el artículo 88 de la Constitución Política, tanto en lo relativo a las acciones populares, como a las acciones de grupo o de clase.

La acción popular es la más usada en el caso de Cartagena. Dentro de estas acciones populares se han realizado dos que se han impetrado por parte de los habitantes de la Ciudadela India Catalina contra el alcaldía y contra la Urbanizadora Gabón. Así como también la promovida por los 
habitantes de Nueva Granada contra la alcaldía y la Constructora El Cerro, caso que fue mencionada con anterioridad en nuestro texto.

\section{Conclusiones}

El derecho a la vivienda, si bien está establecido a nivel constitucional, en nuestro sistema interno forma parte de los derechos sociales, circunstancia que determina, con algunas excepciones, las dificultades relacionadas con el acceso al mismo. Justamente estas dificultades pueden rastrearse en clave histórica, y desde allí sostener que es un derecho que ha venido sufriendo una erosión, en la medida en que la vivienda de interés social (VIS) ha atravesado procesos, que no se desligan de procesos económicos. Por ejemplo, la financiación a través de recursos públicos y, peor aún, con la incursión económica de la banca privada. Por ello, cobra importancia la característica de "vivienda digna", que se ajuste a los parámetros normativos establecidos en la Constitución, y demás desarrollos legales que la reglamentan.

Hoy los problemas son mayúsculos en torno a la construcción de viviendas, y la falta de un mayor control estatal en la materia. El Estado, encarnado en sus instituciones de orden nacional o territorial, es requerido a través de acciones judiciales para el resarcimiento de daños sufridos por los propietarios de vivienda, que generan empresas constructoras inescrupulosas, que pasan por alto los requerimientos técnicos establecidos en la ley, y se aprovechan de un sistema estadal con muchas debilidades en el control de construcciones de este tipo.

De hecho, en lo que se refiere especialmente a la ciudad de Cartagena, existen problemas relacionados con viviendas de interés social que abarca los diferentes sectores de la población; sin embargo, los estratos más pobres son los más afectados. En tal sentido, debería ser de sumo interés para las autoridades, ejercer un control mucho más óptimo, teniendo en cuenta para ello, las lecciones aprendidas de la vulneración del derecho a la vivienda. Como el de la Ciudadela India Catalina y Barrio Nueva Granada entre otros, que han conllevado a que se interpusieran diferentes acciones populares o de acciones de grupo, como consecuencia de las fallas de los organismos de 
control sobre las sociedades constructoras y proyectos urbanos de VIS, que no llegaron a desarrollarse, según lo proyectado.

Sin duda, el control de las construcciones de vivienda de interés social, debe estar reforzado de tal manera, que haya sanciones efectivas e inmediatas sobre las personas jurídicas públicas o privadas. Por ejemplo, en el caso de los constructores, que incurran en la violación de las diferentes normas urbanísticas, deberían ser excluidos de cualquier tipo de proyectos futuros de construcciones de viviendas. Para que así haya una mayor confianza en el grueso de aquella población de menos recursos, que buscan adquirir estas viviendas. Por supuesto, también se debe permitir que los constructores ejerzan bien sus proyectos so pena de aplicárseles sanciones ejemplares.

A pesar de que existen legislaciones especializadas en lo concerniente a la vivienda de interés social en Colombia, como la Ley 388 (artículo 91) ley 810 del 2.003 - decreto 1464 del 2.010 - Ley 1537 del 2012 - Ley 1450 del 2.011 - decreto 975 del 2.004 - POT Cartagena. Consideramos que todo este tema, se debe revisar con mayor profundidad, con el propósito de repensar estos procesos que den lugar a nuevas normativas. Que integren todo de una manera mucho más robusta tanto desde el punto de vista técnico como jurídico. Dándole cumplimiento a las especificaciones normativas internas e internacionales acorde con lo que es una vivienda digna y adecuada, en concordancia y armonizadas con la Declaración Universal de los Derechos Humanos, en su artículo 25, apartado 1 y en el artículo 11 de Pacto Internacional de Derechos Económicos, Sociales y Culturales (PIDESC). Y lo más importante, donde se especifique los controles reales y las acciones legales, inclusive con prisión contra aquellos individuos, que se aprovechen o dañen a las personas más pobres, que urgen de este tipo viviendas de interés social.

También es importante que el Estado eduque a la población sobre estos temas básicos, antes de proceder a negociar una vivienda de interés social. Así como que se establezca la obligación derivada de la buena fe que las constructoras privadas y entidades de financiación, tienen de explicar claramente el alcance de su participación en dichos proyectos.

Así las cosas, debe promoverse el control social, relacionado con las especificaciones técnica y los requerimientos de las diferentes licencias y 
permisos de este tipo de proyectos urbanísticos. Inclusive, en este asunto, se requiere entregarles a los futuros habitantes o propietarios copias de los documentos legales, licencias, planos, etc., para que de alguna manera puedan hacer control de lo que se les está construyendo. Finalmente, podemos afirmar que las carencias normativas y administrativas sin solución, especialmente en cuanto a la Vivienda de Interés Social se refiere, muy seguramente permite avizorar que seguirán los descalabros que han venido sucediendo desde finales del Siglo XX, tanto en Cartagena como en el resto de Colombia.

\section{Referencias}

Alcaldía del Distrito de Cartagena. Decreto 977 DE 2001, "Por medio del cual se adopta el Plan de Ordenamiento Territorial del Distrito Turístico y Cultural de Cartagena de Indias."

Carta Mundial por el Derecho a la Ciudad. En: Revista Paz y Conflictos No. 5 2012.España: Ed. Universidad de Granada.

Constitución Política de Colombia. (2016). Colombia: Editorial Legis.

Congreso de la República de Colombia. Ley 9 de 1989, "Por la cual se dictan normas sobre planes de desarrollo municipal, compraventa y expropiación de bienes y se dictan otras disposiciones."

Congreso de la República de Colombia. Ley 388 de 1997. "Por la cual se modifica la Ley 9 de 1989, y la Ley 2 de 1991 y se dictan otras disposiciones"

Congreso de la República de Colombia. Ley 400 de 1997. "Por el cual se adoptan normas sobre construcciones sismo resistentes".

Congreso de la República de Colombia. Ley 472 de 1998. "Por la cual se desarrolla el artículo 88 de la Constitución Política de Colombia en relación con el ejercicio de las acciones populares y de grupo y se dictan otras disposiciones"

Congreso de la República de Colombia. Ley 546 de 1999. "Por la cual se dictan normas en materia de vivienda, se señalan los objetivos y criterios generales a los cuales debe sujetarse el Gobierno Nacional para regular un sistema especializado para su financiación, se crean instrumentos de ahorro destinado a dicha financiación, se dictan medidas relacionadas con los impuestos y otros costos vinculados 
a la construcción y negociación de vivienda y se expiden otras disposiciones".

Congreso de la República de Colombia. Ley 810 de 2003. "Por medio de la cual se modifica la Ley 388 de 1997 en materia de sanciones urbanísticas y algunas actuaciones de los curadores urbanos y se dictan otras disposiciones."

Congreso de la República de Colombia. Ley 902 de 2004. "Por la cual se adicionan algunos artículos de la Ley 388 de 1997 y se dictan otras disposiciones."

Congreso de la República de Colombia. Ley 1116 de 2006. "Por el cual se establece el régimen de insolvencia empresarial en la república de Colombia."

Congreso de la República de Colombia. Ley 1537 de 2012. Por la cual se dictan normas tendientes a facilitar y promover el desarrollo urbano y el acceso a la vivienda y se dictan otras disposiciones.

Padilla Hernández, Eduardo (2007), Derecho Urbano. Santafé de Bogotá D.C.: Librería Ediciones del Profesional

Vargas-Chaves, I., \& Marrugo-Salas, L. (2015) La responsabilidad social empresarial como criterio orientador para sostenibilidad y la ética de las actividades del sector bancario. Jurídicas, 12(2), 42-57.

Fuentes on line:

Canal El Sol de Cartagena. (2010). Atropellos en la India Catalina por parte de la Súper Intendencia de Sociedades. Recuperado de:https:// www.youtube.com/watch?v=kHXmjaiPEvg

Defensoría del Pueblo (2014). Vivienda Digna. Recuperado de: http:// www.defensoria.gov.co

Fundación Sumapaz, (2014), Derecho a la vivienda digna y adecuada en la Comuna 3 Manrique. Recuperado de http://www.sumapaz.org/ files/Derecho\%20a\%20la\%20vivienda.pdf

Periódico el Universal. Recuperado octubre 27 de 2015. http://www.eluniversal.com.co/cartagena/local/loma-del-marion-amenaza-nuevamente-nueva-granada-50470

Periódico el Universal. Recuperado abril 23 de 2015. http://www.eluniversal.com.co/cartagena/local/80-de-construcciones-en-cartagena-son-ilegales-73575 
Periódico El Universal. (2014). "Alto riesgo", ¿hasta cuándo? Recuperado de: http://m.eluniversal.com.co/cartagena/editorial/\%E2\%80\%9Calto-riesgo\%E2\%80\%9D-\%C2\%BFhasta-cuando, octubre de 2014.

Periódico El Universal. Otro Alud En El Rodeo. Recuperado de:http:// www.eluniversal.com.co/cartagena/local/otro-alud-en-nueva-granada. Octubre de 2014.

Periódico El Tiempo). Por temor a volcanes de lodo, 400 familias piden reubicación en barrio de Cartagena. Recuperado de:http://www.eltiempo.com/archivo/documento/CMS-5319427. Octubre de 2014.

Periódico El Tiempo: http://www.eltiempo.com/colombia/otras-ciudades/ el-deficit-de-vivienda-social-en-cartagena-47066 octubre de 2014

http://www.cartagena.gov.co/Cartagena/secplaneacion/Documentos/pages/ pot/files/normograma/ACUERDO_23_BIS_MANUAL_DE_ORDENAMIENTO_ADMINISTRATIVO_DEL_ESPACIO_URBANO.pdf

https://es.scribd.com/doc/92156739/Demanda-Accion-Pupular-Ambiental-Ganada-Ucic

https://es.scribd.com/doc/256034395/Ciudadela-India-Catalina-Accion-Popular-Rad-13001-23-33-000-2012-00034-00-Fallo-Primera-Instancia

https://es.scribd.com/doc/92156739/Demanda-Accion-Pupular-Ambiental-Ganada-Ucic

https://es.scribd.com/doc/256034395/Ciudadela-India-Catalina-Accion-Popular-Rad-13001-23-33-000-2012-00034-00-Fallo-Primera-Instancia

https://es.scribd.com/doc/261942655/Accion-Popular-Nueva-Granada-Sentencia-Tribunal-Administrativo-Bolivar-Rad-004-1999-0002-00-Reubicacion

https://es.scribd.com/doc/261943411/Accion-Popular-Nueva-Granada-Sentencia-Consejo-Estado-Rad-AP-118-Confirmada-Reubicacion 
